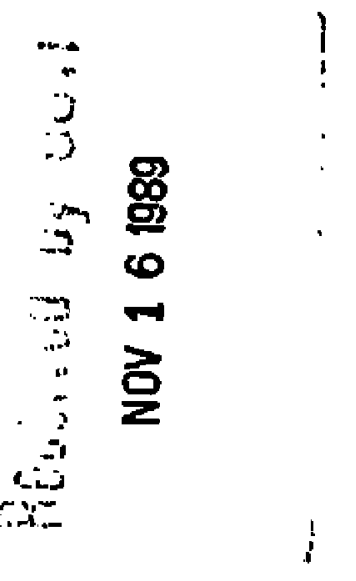

\title{
SLAC/AP--76
}

DE90 002803

\section{OPTIMIZING THE AVERAGE LONGITUDINAL PHASE OF THE BEAM IN THE SLC LINAC*}

\author{
KARI. L. F. BANE \\ Slenfurd Linear Accelemtor Center \\ Stanfond Uniucraity, Slanford, Califomia 9/909
}

- Work supporked by the US Department of Energ, contract DE - ACO3 - 7651'00515. 


\section{InTumblit:rion}

The luminusity of the SLC dppends on the energy opectrum of each beam at 1 lu" final forus. In turn, the energy spectrum is deternined by the beam's average linac phare $\phi_{0}$. For good luminosity the spectrum needs to be suffiriently narrow to fit wetl within an energy aperture of $\pm .6 \%$. By riding the beam at the proper pinase aluead of the rf erest the contribution to the energy spread due to the if wave can br made to compensate that due to the longitudinal wakefield, resulting in a narrowed spectrum. For example, wilh a bunch population of $5 \times 10^{10}$ and a bunch lenglh of $1.5 \mathrm{~mm}$ almost all the beam can be located within $\pm .3 \%$ in this way.

Besides ita direct effect on the SLC luminosity, $\phi_{0}$ also affects the population of the energy tails. And particles with energies far from the nominal value can undergo large orbit excursions in the linac. Both energy and orbit tail particles cen reduce the effective luminosity, if they reach the final focus, by increasing the detector background. But if we assume that the collimatoro are adjusted properly, then both types of tail particles are clipped before the beam ever reaches the debector. Normally, thesefore, backgrounds should not be an important consideration in choosing \$o.

If we clioose to to ninimize the $\mathrm{tm}$ deviation of the final energy spectrum

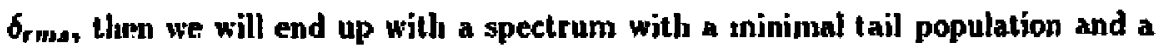
somewhat narrow core size. In a procedure nucant to approximate this calculation the SLC operators were - at one time - told to adjust the overall plinse of the linac to yield the cnergy distribution which. when fit to a gnussian, gives the gaussian with the smallest width. (The rms energy deviation itsalf cannot be measured since (he energy (ajls tend to be below the nolse of the measurenuent.) One problem with 
this procedure is that the energy distribution is notmally not gaussian. Another is that it tends to minimize the width of the beam core, which, as we shall sce, does not in general result in the maximum luminosity.

The relation of $\phi_{0}$ to the final energy spectrum in the SLC linac has been studied by many people over the years (see, for example, Refs. 1-6), with unuch

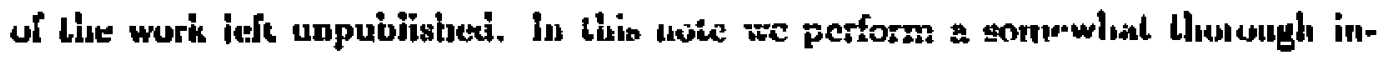
vestigation of the problem. First we describe the calculation muthod, and discuss some common features of the energy spectrum. Then we calculate the value of कo that mininizes $\gamma_{\mathrm{rm}}$ for the conceivable range of buich population and bunch Jengths of the SLC linac. This is followed by luminosity calculations, including the sensitjvily of Juminosis: to variations in $\phi_{0}$. Finally we suggeat a practical method of implementing the proper phase setting on the real machine.

\section{Til: Enengy SPectrum at tie End of the Linac}

The final linac energy, at position $z$ within the bonch, is givnn by

$$
E(z)=E_{0}+E_{a} \cos \left(k_{r f} z+\phi_{0}\right)-e^{2} N W(z)
$$

with $E_{0}$ the initial energy (in this paper we ignore the beam's initial energy devia. tion). $k$. the total peak of energy gain, $k_{, j}$ the of wave number, $N$ the total bunch population ard $W(z)$ the longitudinal wake of the bunch for the entire linac. A negative phase means a position toward the front of the erest. Note that $W(z)$ depends on the bunch shape. If the final desired energy is $(E\rangle$ then the lotal peak energy gajn needed is

$$
E_{a}=\left(\langle E\rangle-E_{0}+e^{2} N\langle W\rangle\right) / \cos \phi_{0}
$$

if the charge distribution is symmetric about $z=0$. The average of the wakeficld 
weighted by the charge distribution is denoted by $(W)$. The quantity $(W)$ is sometimes called the loss factor; the total leam induced energy loss $E_{\text {weete }}$ is given by the product $e^{2} N(W)$.

The energy distribution; when normalized to unity, is given by

$$
\frac{d n}{d E}=\frac{\langle E\rangle}{N} \sum_{x(E)} \frac{d N / d z}{|d E / d z|}
$$

with $\delta \equiv E /(E)-1$, the energy deviation. The numerator in the aum is the charge distribution, the denominator is the derivative of Eq. (1). To evaluate these functions we first need to solve Eq. (1) fot $z(E)$. Then if there is more than one solution ( $E(z)$ is not, in general, monotonic) the sum must be performed over all of them. We note from Eq. (3) that the energy distribution besomes infinite wherever $d E / d z=0$; its integral, bowever, is always finite. (We could include the effect of the incoherent energy spread by convolving its distribution with the results of our calculation. The new spectrum would then be everywhere finitc. But since the incoherent contribution is small - in the SLC its rms width in .02\% - and not important for our purposes, we will not include it in our calculations.)

We have written a computer program to calculate the final encrgy distribution of a gaussian bunch in the SLC limar. For afl the results to be presented in thise paper the parameter $E_{\mathrm{a}}$ bas been adjusted so that $(E)=47 \mathrm{GeV}$; the initial energy $E_{0}=1.153 \mathrm{GeV}$; the total length of accelerating structure (needed for calculating $W(z))$ is 2744 in. The bunch wake is fisund by convolving the charge distribution with the delta function wake of the SLAC litac. Fig. 1 displays $W(z)$, over the whole linac, for gaussian bunches with $\sigma_{\Perp}=.5,1.0,1.5 \mathrm{~mm}$. Thus, for example, we sce that at $N=5 \times 10^{10}$ and $\sigma_{2}=1 \mathrm{~mm}$ the peak of the induced loss for the 
whole linac is $2 \mathrm{GeV}$, and is experienced by particles at 1 mun behind bunch center. The expression

$$
\left(\frac{F_{\mathrm{rabe}}}{\mathrm{GeV}}\right)=.5\left(\frac{N}{10^{10}}\right) \exp \left[-.6\left(\frac{\sigma_{\mathrm{r}}}{\mathrm{mm}}\right)^{-35}\right] \quad \sigma_{z} \leq 5 \mathrm{~mm}
$$

approximates the total beasn induced energy loss to good accuracy.

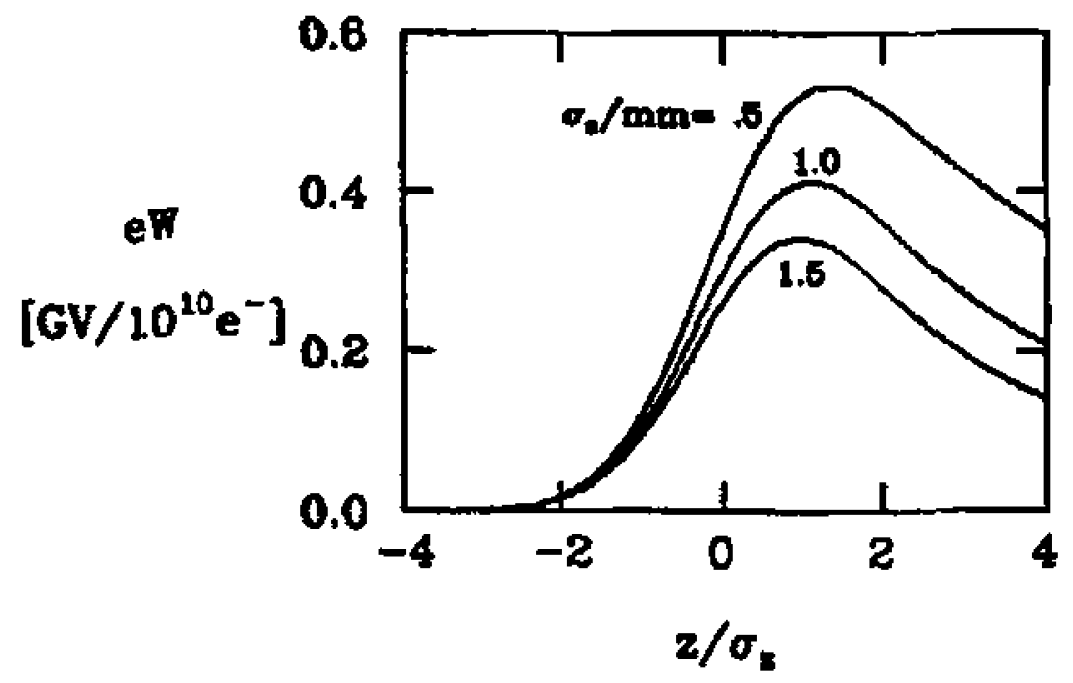

Fig. 1. The bunch wake, over the whole SLC linac, for gausian bunches with $\sigma_{1}=.5,1.0$ and $1.5 \mathrm{~mm}$.

Let us first consider the case when $N=3 \times 10^{10}$ and $\sigma_{x}=.75 \mathrm{~mm}$. We find that there is a range of values $\phi_{0}<0$ for which the linear part of the wakefield and of the if wave lead to cancel ench other to some extent, resulting in a somewhat natrow, "double horned" distribution" - i.e. one having two infinite peaks, Within this rasige, as the bunch is moved forward - away from the if crest the liorn spacing narrows and the tail population grows; as it is moved backward - toward the crest -. the opposite happens. The rms energy devialion $\sigma_{\mathrm{rmg}}$ is minimized, and equals, $28 \%$, if we set to to -10.7 degrees. The top lelt plot of Fig. 2 gives the 


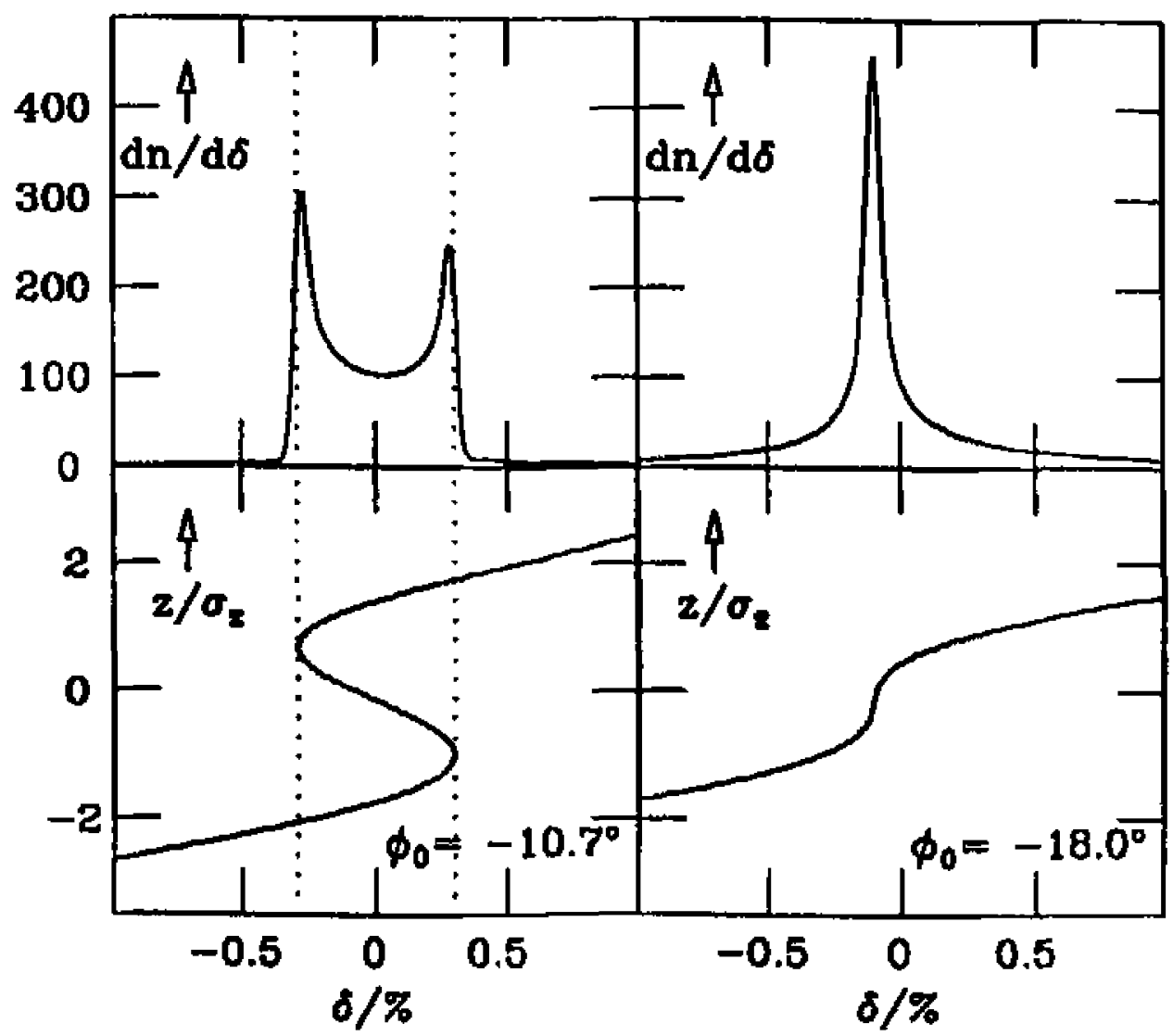

Fig. 2. The energy distribution (top frames) and the function $\delta(z)$ (bottom frames) at the end of the SLC linac, when $\phi_{0}=-10.7$ degroes (left) and -18.0 degrecs (right). In both cases $N=3 \times 10^{10}$ and $\sigma_{f}=.75 \mathrm{~mm}$.

energy distribution. For this figure, in order to show the lieights of the peaks, we have convolved our calculation with a gaussian of $.02 \%$, which represents the contribution of the incoherent energy spread. I'tu luttom plot displays the function $\delta(z)$; the dotted lines give the solutions of $\delta^{\prime}(z)=0$, which we call the horn edges. The horns coalesce when the beall is moved forward to $\phi_{0}=-17.4$ degrees. The riglt two frames of Fig. 2 show the centergy distribution and $d(z)$ when the beam is moved just beyond this point, $10-18.0$ degrees. Then rum enurgy deviation is 
.67\%. We note that the core has narrowed while the tail population has increased. A measurement technique that minimizes the core and is iascnsitive to the tails will find - 10.7 degrens a worse choice of phase than - 18.0 degress. However, in the formet case only $3 \%$ of the beam is outside the $\pm .5 \%$ aperture; in the latier case $24 \%$ is outside this window.

\section{Miniatzing thy Rus Enehgy Spread}

We hnve calculated the final energy spectrum of gaussinn bunches in the SLC, for bunch populations of $N=1,2,3,4,5,7 \times 10^{10}$ and lengths $\sigma_{2}=.5, .75,1$, $1.25,1.5 \mathrm{~mm}$. In each case the parameler $\phi_{0}$ was adjualed to minituize the rms energy deviation $\delta_{r m a}$. Fig. 3a displays the value of $\phi_{0}$ that minimizes $\delta_{\mathrm{rm}}$ as a function of $\sigma$, for several values of bunch population. As we increase the current or decrease the bunch length the beam needs to move farther off crest for oplimal energy spread compensation. For bunches short compared to the $f f$ wavelength the optimal phase is found when the linear part of the rf cancels the average slope of the wahe; i.e. when ${ }^{6}$

$$
\sin \phi_{0}=-\frac{e^{2} N\left(W^{\prime}\right)}{k_{r} E_{a}}
$$

with $\left(W^{\prime}\right)$ the average value of the slope of the wake weighted by the charge distribution. In our chse the curves can be approximated by

$$
\left(\frac{\phi_{0}}{d c g}\right) \approx-2.25\left(\frac{N}{10^{10}}\right)\left(\frac{\sigma_{x}}{\mathrm{dim}^{2}}\right)^{-1.4}
$$

(ser the dutted curves in Fig. 3a).

Pig. 3h gives the resulting figure of merit $\delta_{\mathrm{rm}}$. We see that in order to keep the ruls sinergy sprenul wmall it is desirable to increase the bunch length as we 
incretse the curront. 'The dasled curve shows the rno deviation due to the rf curval ure nlome, whicl, is given by $\delta_{r m s}=k_{r}^{2} \sigma_{s}^{2} / \sqrt{2}$. Whe note that in some cases tlu wimimum encrgy sprend is less when the wakeljuld is included than when it is nol.

Whenerer the carrent is gufficiently high and the bunch length sufficiently short the optimal spectrum will have a double horned shape. In Fig. 3e we display the horn separation $\Delta \delta_{h}$ of the optimal distribution. In all cases approximately $95 \%$ of the bean is found butween the horns. The $N=1,2,3 \times 10^{10}$ curves do not reach, respectively, to bunch length values of $1,1.25,1.5 \mathrm{~mm}$ since at these lengths Llie optimal distribution is no longer double horned. We note that these curves are very similar to those of Fig. 3h, with $\Delta \sigma_{h} \approx 26_{\mathrm{rmos}}$, due to the fact tbat a major portion of the charge is localed in the vicinity of the horns. The curves are almost straight lines; they can be approximated by

$$
\left(\frac{\Delta \delta_{h}}{\%}\right) \approx\left(\frac{N}{10^{10}}\right)\left[1.11-.38\left(\frac{\sigma_{2}}{\mathrm{~mm}}\right)\right]
$$

(see the dotted lines in the plot).

\section{Optumtzing THE LUMtnostry}

'Tho luminosity depends on boll: beams' energy spectra at the find focus. After the linac the bunches traverse the arcs on the way to the final focus. Due to synchrotron radiation in the arcs each beam loses $1 \mathrm{GeV}$ of energy and its spectrum is smeared by $.08 \%{ }^{2}$ Since these effects are winall wr will ignore them in all calculations that follow. We will further assume that the energy aperture of the arcs is at least as large as that of the encrgy collimator/final focus syrtem, and that the cnergy spectruin at the final focus is essentially the same as nt the end 


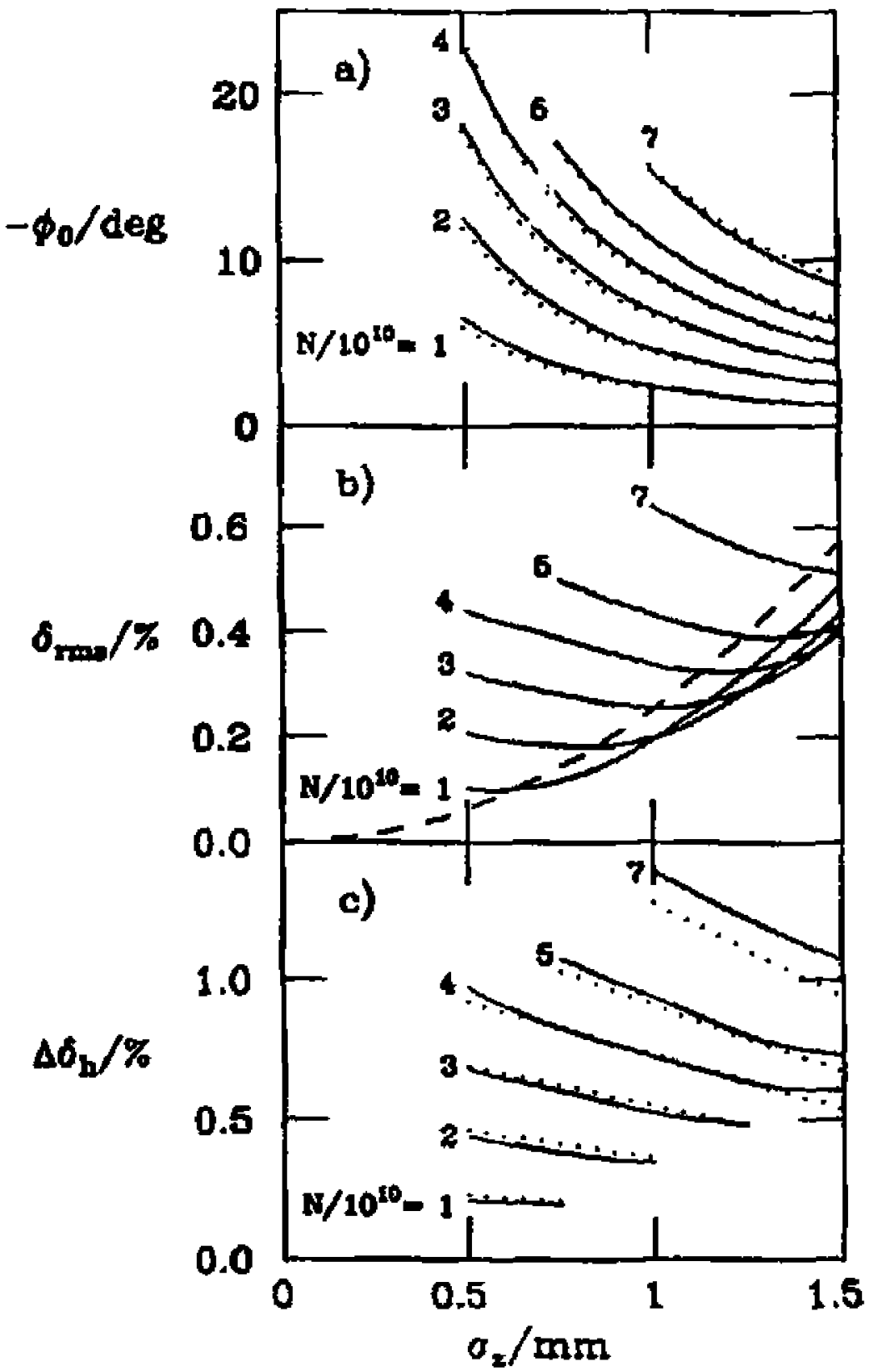

Fig. 3. The average linac phase that minimizes $\delta_{r m o}(a)$, the resulting $m$ sms energy deviation (b), and the separation of the horns (c), as functions of bunch length, for several values of bunch population. 
of the linac. In addition to the energy spectrum, the luminosity depends on each bearn's emittance at the final focus, which in turn depends on the orbit and optica errors in the linac, arcs and final focus.

Let us assume that the beams are transversely upperturbed gausian, that the Juminosity is not degraded by detector background and that we can ignore the luminosity enhancement of the beam-beam effect. Then by knowing the energy spectrum of each beam at the final focus and the energy reaponse of the final focus - i.e. the final spot aize as function of energy deviation - we can carily calculate an ideal luminogity. For example, a luminosity factor for two identical beams colliding head-on can be written as

$$
r_{\lim }=2 \sigma_{x}(0) \sigma_{y}(0) \int_{\delta_{\min }}^{\delta_{m u}} \frac{d n}{d \delta}(\delta) d \delta \int_{\delta_{\min }}^{\delta_{\operatorname{man}}} \frac{d n}{d \sigma^{\prime}}\left(\delta^{\prime}\right) \frac{d \delta^{k}}{\bar{\sigma}_{z}\left(\delta, \delta^{\prime}\right) \bar{\sigma}_{y}\left(\delta, \delta^{\prime}\right)}
$$

with $\sigma_{x}(\delta), \sigma_{j}(\delta)$ the apot oizes; with $\bar{\sigma}_{z}^{2}\left(\delta, \delta^{\prime}\right)=\sigma_{x}^{2}(\delta)+\sigma_{z}^{2}\left(\delta^{\prime}\right)$, and oimilarly for $\bar{\sigma}_{\sigma \text {. }}$ The limita of integration $\delta_{\min }, \delta_{\operatorname{mex}}$, represent the axceptance limito of the energy collimator/final focus syotem. We note that rhm gives the relative luminosity reduction due to only the longitudinal effects (it becomcs 1 for monoenergetic beams). As such it represents an upper bound on the achievable luminosily, ance any emittance growth will reduce the luminosity further. When comparing the luminosities for differeat currente, assuming the emittances are the game, we need to compare the quantities $r_{\mathrm{mm}} N^{2}$.

If we suppose that the energy response of the final focus is flat within the aperture $\Delta \delta_{a}\left(\equiv \delta_{\max }-\delta_{\min }\right)$, then the luminosity is just proportional to the square of the charge found within it, assuming also that the two beams are equal and collide beston. Setting to to minimize $6_{r m}$ will then result in almout the 
optimal luminusity if the distribution is double horned with $\Delta \delta_{h}<\Delta \delta_{\text {a, }}$ aines then at least $95 \%$ of the beam will be within the nperture. This siluation can be improved upon slightly if we increase the horn separation (up to a maximum of $\left.\Delta \delta_{a}\right)$ by moving the bemm nearer the if crest. If the horn separation that minimizes $\delta_{r m e}$ is greater then $\Delta \delta_{e}$, then the horns need to le brought withio the aperture (by moving the beam farther off creat) for maximum luminusity.

The encrgy nuponse of the SLC final focus does depend on energy deviation, as well as on the cmittance Fig. 4 shows calculation resulta, produced by K. Brown (son ale Rer. 8), of the final apol size dependence on energy deviation for the SLC, for beans with typical normalized emillances. These are 5 and $3 \times 10^{-3} \mathrm{rm} \mathrm{lo} \mathrm{a}$ and $y$ respectively at the final focus (corresponding to $3 \times 10^{-5} \mathrm{~m}$ in each plane at the end of the linac). It is also assumed that the beams have come through the North Arc and that the final focus is configared for the Mark II delector. Although $\sigma_{y}$ is rather Ant over the whole $\pm .5 \%$ range, $\sigma_{x}$ is flat only over about $\pm_{n} 3 \%$. 'The energy aperturs: of the SLC energy collimator/final focus systen can be taken to th $\pm .5 \%$.

We hove numcrically solved Eq. (8) for the bcam distributions portrayed in lig. 2 for $N=3 \times 10^{10}$ and $\sigma_{4}=.75 \mathrm{~mm}$. We find the luminosity factor is .86 and .51 for respectively the distribution that minimizes $\delta_{r m}$ and the one whict lies one narrow peak. Cloarly, minimizing the core width does not, in genern, maximize the luminusity. Wo have repealed the calculation for beams with various leugthy and

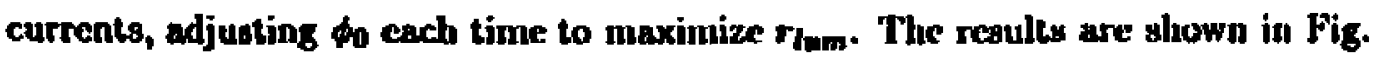
5. The top frame gives the phase to which optimizes the luminosity. The curves for $N=1,2,3 \times 10^{10}$ are almost identical to those of Fig. 3a. For the bigher currents the benm need to move frrther of crest, resulting in a narnower horn 


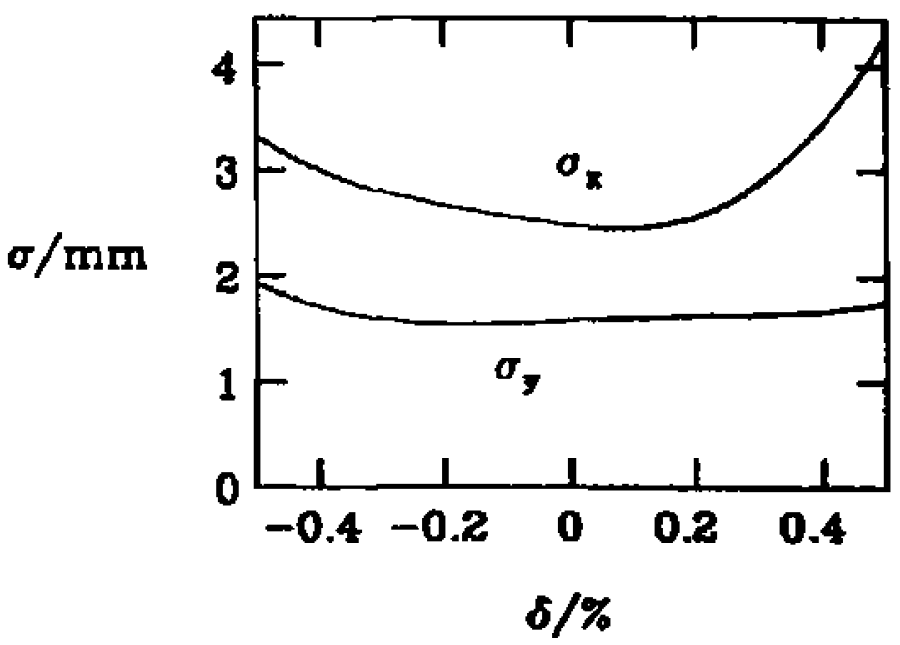

Fig. 4. The fiual gpot size a function of energy deviation in the SLC when $x$ and $y$ emittance in the final focus are, respectively, 5 and $3 \times 10^{-5} \mathrm{~m}$; the beams have come through the North Arc; the find locus is configured for the Mark II. (Produced by K. [3rown.)

spacing, if we want to maximize the luminosity rather than ininimize $\delta_{r m}$. The maximum luminosity is given in Fig. itb. We ses that, although the dependence on bunch length is weak, as the current is increased the bunch thould be lengthened to naximize the luninosity.

Given a value of bunch population, what is the optimal choice of bunch length? The orbit tolerances of the beam in the SLC linec tend to increave with decreaning bunch length. However, as we have juat acen, for a given current it the bunch is too short we will need to move very far off crest to compenaste the longitudina wakefield, and we will also lose some luminosily. As a compromine between these conaideratione we suggest at, respectively, $N=1,2,3,4,5,7 \times 10^{10}$ choosing the bunch length $.5, .75, .75,1.0,1.0,1.25 \mathrm{~mm}$.

Fig. 6a digplays $r_{\text {lem }}$ as funclion of $\phi_{0}$, for the suggested currant/bunch length 


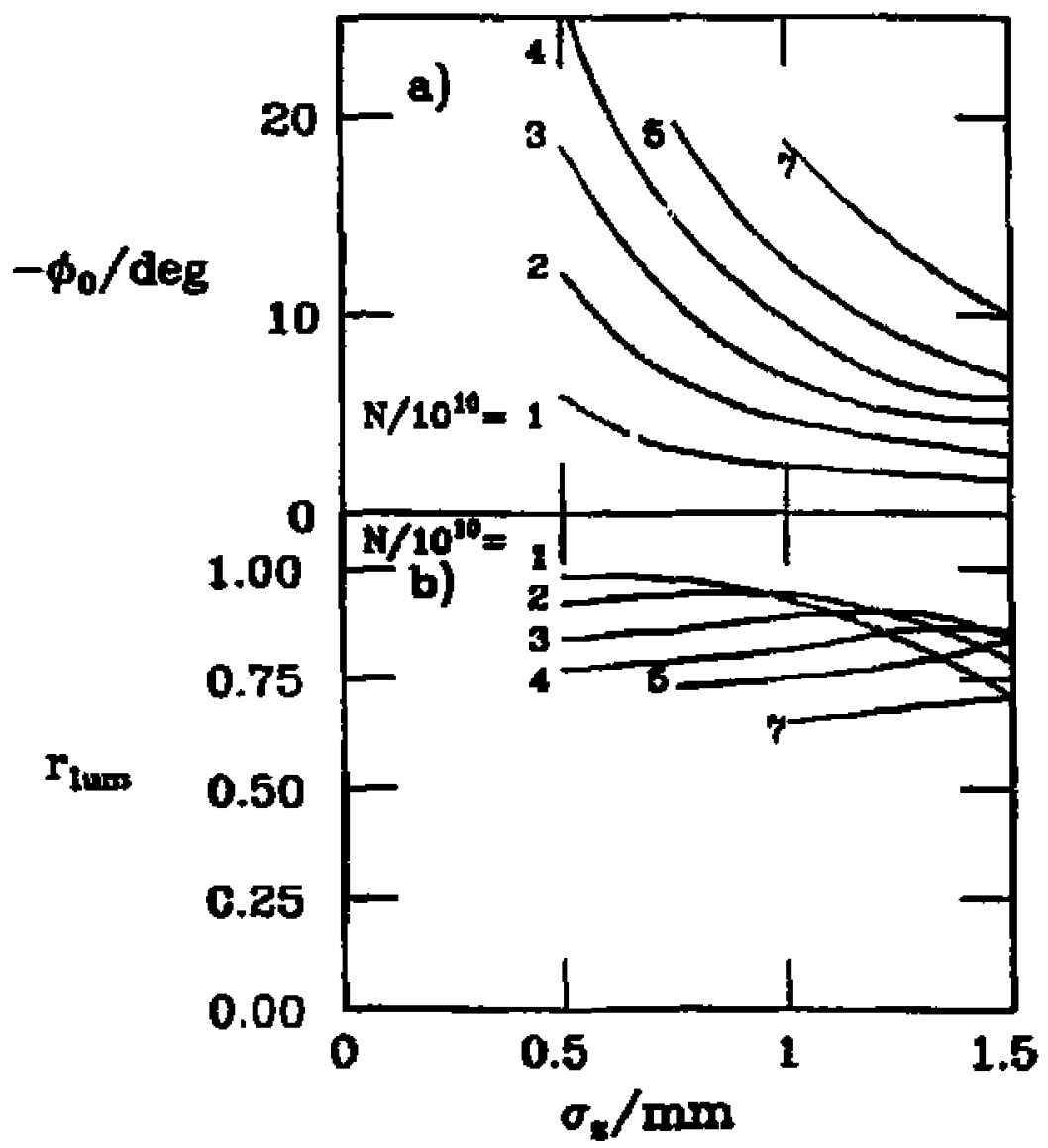

Fig. 5. The average linac phase that maximizes $r_{\text {/am }}(a)$, and the resul'ing luminosity factor (b), as functions of bunch length for several values of bunch population. The spol functione of Fig. 4 were used in the calculations.

combinations, assuming the spot size functions of Fig. 4; Fig. 6b gives the horn spacing of the corresponding energy distibution. We clearly sce that near its maximnum value the luminosity is rather insensitive to the average of phase and to the horn spacing. We also note that the curves are nol symmetric about their maxima. Beginning somewhere just under $\Delta \delta_{h}=1 \%$, as the horn spacing is increased the luminosity drops quickdy. 


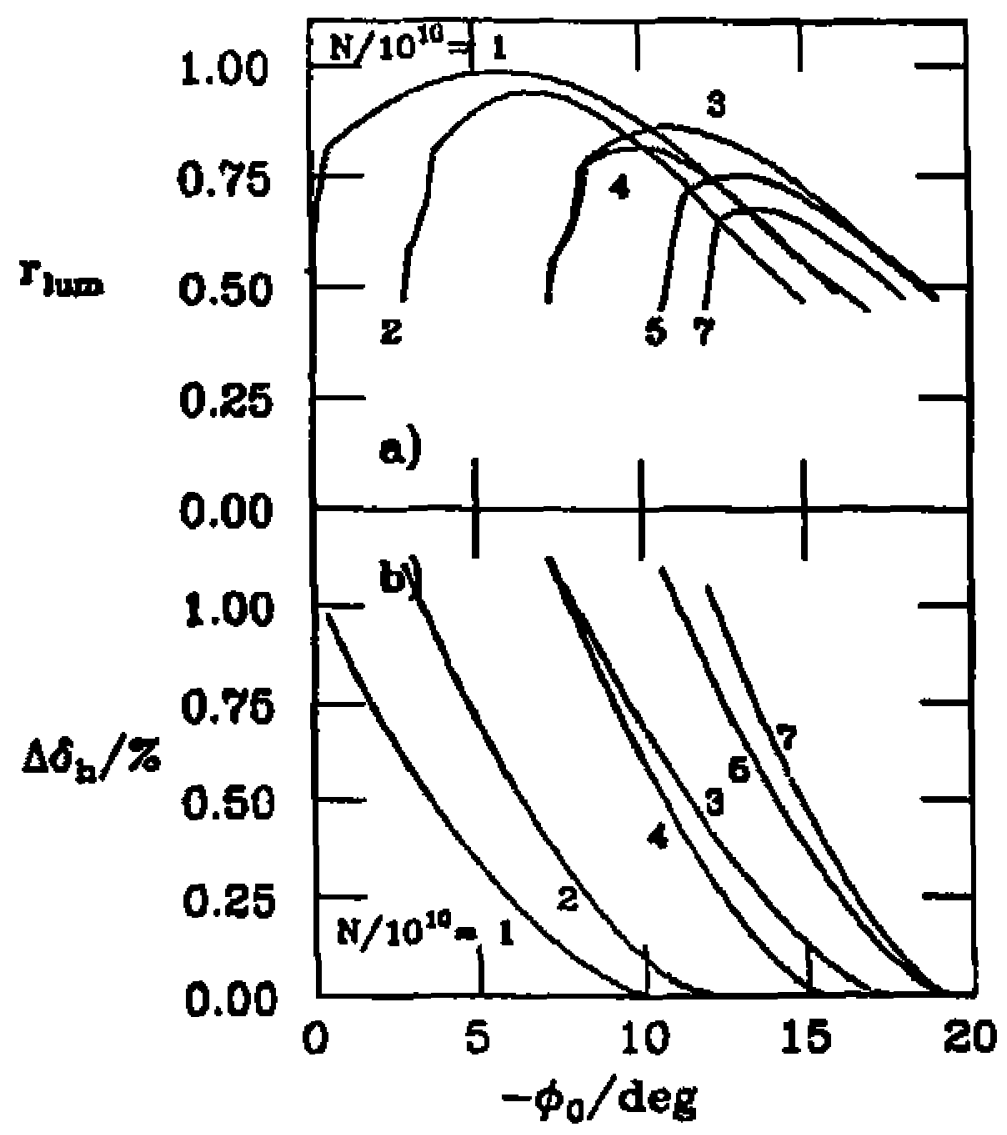

Fig. 6. The luminosity factor (a) and the horn separation (b) over a range of values of $\phi_{0}$, for the suggested current/bunch length combinations. The currents are $N=1,2,3,4,5,7 \times 10^{10}$, and the correaponding bunch lengths are $.5, .75, .75,1.0,1.0,1.25 \mathrm{~mm}$. The epot functions of Fig- 4 were ured in the calculations.

Table 1 gives the maximum values of rimm shown in Fig. 6. We see that by going from I $107 \times 10^{10}$ the luminosity can increase by the factor $49(.08 / .98)=34$, if the emittance is uncharged. Also shown for the optinal situation are the fraction of the beam within the energy acceptance $n_{ \pm .5 \%}$, the phase $\phi_{0}$, and the horn spacing $\Delta \delta_{h}$. The pairs of parenthetical values are the increments of the given paranseter 
which result in a reduction of $r_{\text {imm }}$ of .05 ; the first of each pair by going more oft crest, the sccond by moving toward the rf crest.

Table 1. The optimum luminosity for typical bunch propertics using the final Iocus nesponse functions given in Fig. 4. The parenthetical values are the increments which result in a zeduction of $r_{1 / m}$ by .05 .

\begin{tabular}{|c|c|c|c|c|c|}
\hline$N / 10^{10}$ & $\sigma_{n} / \mathrm{mm}$ & $H_{\text {Imm }}$ & $n_{ \pm .5 \%}$ & $-\phi_{0} / \mathrm{deg}$ & $\Delta \delta_{h} / \%$ \\
\hline 1 & .50 & .98 & $1.00(-.02 /+.00)$ & $5.9(+2.7 /-3.0)$ & $.25(-.20 /+.34)$ \\
\hline 2 & .75 & .94 & $.99(-.03 /+.01)$ & $6.8(+1.9 /-1.8)$ & $.43(-.22 /+.27)$ \\
\hline 3 & .75 & .86 & $.96(-.04 /+.03)$ & $10.7(+2.5 /-1.9)$ & $.59(-.30 /+.27)$ \\
\hline 4 & 1.00 & .82 & $.95(-.04 /+.03)$ & $9.7(+2.1 /-1.5)$ & $.64(-.30 /+.28)$ \\
\hline 5 & 1.00 & .75 & $.92(-.06 /+.03)$ & $12.7(+2.4 /-1.5)$ & $.71(-.35 /+.26)$ \\
\hline 7 & 1.25 & .68 & $.88(-.06 /+.03)$ & $13.6(+1.7 /-1.3)$ & $.72(-.30 /+.27)$ \\
\hline
\end{tabular}

The results of Figs. 5-6 and Table 1 are valid for typical current SLC operation. If the spot size functions change, for example due to a change ia the beam's emittance, or because the final focus is reconfigured for the SLD delector, the results will be somewhat different.

\section{Finding tife Desiaed Rf Phase on thie SLC}

Ideally, to find the optima SLC linac phase the luminosity should be measured and then the phase adjusted to maximize it. This being impractical we suggest that the calculated result given in Table 1 be used for finding the optimal phase setting. In the SIC linac the phase of each beam is adjusted by the phase ramp, a knob which changes the relative phase of the beam with respect to the linac by an amount $\Delta \phi_{\text {ramp. }}$. What is the value $\Delta \phi_{\text {ramp }}$ that achicves an average linac phase 
\$o? If initially the phases of all the klystrons are identical, with the lx:ann riding on crest, then $\Delta \phi_{\mathrm{ramp}}=\phi_{0}$. Normally, however, the pliases of the klystrons are not all lined up, primarily in order to take advantage of BNS damping. In such a case we can approximate $\Delta \phi_{\text {ramp }} \approx \phi_{0}-\left\langle\phi_{b}\right\rangle$, with $\left\langle\phi_{b}\right\rangle$ the average value of the phase: of the beam with respect to the klystrons, as long as the beam is near the crest in all sectors (within, say, 30 degrees). However, rather than setting the overall linac phase to achieve the desired value of $\phi_{0}$ (as given in Table 1) directly, we suggest measuring the spectrum width and using it to determine the proper phase selting.

In the SLC the energy apectrum is obtajned from an image of the beam at a high dispersion point at the end of the linac. In the set-up procedure the beam's average phase, initially near 0 , should be reduced (by using the phase ramp) until a double horned diatribution with the desired horn separation is found (see Table 1). At higher currents it is important that the linac orbit be good, so that the measurement is not spoiled by emittance growth or orbit tails. In addition, measurements far beyond the optimal phase should be avoided, since as the beam is moved to more negative values of phase the BNS damping is continually weakered, which will also tend to lead to emittance growth.

One practical problem with this procedure is that the resolution of the measurement has an rms value of $.15 \%$, which will tend to obscure the horns and make it impossible to measure spots with a full-width-at-half-maximum (FWHM) of less than $.3 \%$. Therefore, when $N=1-2.5 \times 10^{10}$ we suggest adjusting the phase until the FWHM of the measured distribution is .5\%, which is large compared to the: resolution. From Table 1 we see that the luminosity will still be nearly optirral. At higher currents, where we are no longer resolution limited, the phase fhould be: adjusted to give a FWHM equal to the value of $\Delta \delta_{h}$ given in Table 1. 


\section{ACKNOWLEDGEMENTS}

The author thanks Karl Brown as well as Mark Rose, John Seeman and the alher members of the Linac Group for helpful discussions.

\section{REFERENCES}

1. SLAC Linear Collider Conceptual Deaign Report, SLAC-229, p. 117 (1980).

2. John Seeman and Joha Sheppard, "Special SLC Linac Developments," SLAC-PUB-3944 (1988).

3. The SLC Detign Handbook, p. 2-2l (1984).

4. Rue Stiening, "Dynamic Beam Loading Compensation and Energy Spectrum in tine SLC," SLAC-CN-110 (1981).

5. John Seeman, GIAT Note, January 1986.

6. Karl Bane, "Wakefield Effects in a Linear Collider," SLAC-PUB-4169 (1986).

7. Karl Bane and Perry Wilson, Procedings of the $11^{\text {th }}$ Int. Conf. on HighEnergy Accelerators, CERN (Birkhāuser Verlag, Basel, 1980), p. 592.

8. Karl Brown, "Scaling of the SLC Find Focus System," SLAC-PUB-4B11 (1989).

9. Mark Ross, private commumnication. 


\section{DISCLAIMER}

This report was prepared as an account of work sponsored by en agency of the United States Government. Neithes the United States Government nor any agency thereof, not any of theif employees, makes any warranty, express or implied, or assumes any legal liability of responsibiltiy for the accuracy, completeness, or usefulness of uny information, apparatus, product, or process diselosed, or represents that its use would not infringe privately owned rights. Reference herein to any specific commercial product, process, or service by trade name, trademark, manufacturer, or otherwise does not necessarily constitute of imply its endorsement. recommendation, of favoring by the United Stotes Government of any agency thereof. The views and opinions of authors expressed herein do not necessarily state or reflect those of the United States Government or any agency thereor. 